\title{
Taksiciler - Uber Tartışmasına Tüketici Gözlüğünden Bir Bakış: Uber Platformunu Kullanma ve Tavsiye Etme Niyetini Belirleyen Etkenler Üzerine Bir Araştırma
} (Araştırma Makalesi)

A View from the Consumers' Glasses on the Taxi-Uber Debate: A Study on the Factors Determining the Intention to Use and Recommend Uber Platform Doi: 10.29023/alanyaakademik.689951

\section{Hakan KİRACI}

Doç.Dr., Muğla Sitkı Koçman Üniversitesi, hakan.kiraci@yahoo.com

Orcid No: 0000-0001-9230-3102

\section{Ruşen AKDEMİR}

Arş.Gör., Muğla Sitkı Koçman Üniversitesi, rusenakdemir@mu.edu.tr

Bu makaleye atıfta bulunmak için: Kiracl, H. \& Akdemir, R. (2020). Taksiciler - Uber Tartışmasına Tüketici Gözlügünden Bir Bakıș: Uber Platformunu Kullanma ve Tavsiye Etme Niyetini Belirleyen Etkenler Üzerine Bir Araştırma. Alanya Akademik Bakış, 4(2), Sayfa No. 425-444.

\section{Anahtar kelimeler: \\ Paylaşım ekonomisi, Türkiye, Uber, paylaşım niyeti, güven.}

Makale Geliş Tarihi: 16.02.2020

Kabul Tarihi: 05.05.2020

\section{ÖZET}

\begin{abstract}
Son yıllarda etkisi günden güne çoğalarak hissedilen paylaşım ekonomisinin amiral gemilerinden biri olarak nitelendirilen Uber platformu, AirBnb ile birlikte paylaşım ekonomisinin çözümlenmesi amacıyla pek çok bilimsel araştırmaya konu olmakta ve aynı zamanda iş modeli / faaliyetlerine ilişkin medya araçlarında haber olarak yer almaktadır. Ülkemizde kisitll bir alanda faaliyetlerini sürdüren Uber, haksız rekabete yol açtı̆̆ düşüncesiyle özellikle taksici esnafin zaman zaman tepkilerine maruz kalabilmektedir. Taksici mi Uber mi kim haklı? tartışmalarından slyrllarak, ülkemizde de yasal niteliği tartışmalı olan bu paylaşım sisteminin kullanıcıları / potansiyel kullanıcıların yaklaşımlarını ortaya koymak bu araştırmanın amacını oluşturmaktadır. Bu noktadan hareketle internet ortaminda yapılan anket çalışmasıyla; sosyal etki, güven, varolan paylaşım davranışları ve beklenen yarar türlerinin Uber sistemini kullanma ve kullanımını tavsiye etme niyeti üzerindeki olası etkileri incelenmektedir. Ülkemizde son yıllarda tartışma konusu olan Uber girişiminin tüketici yönlü değerlendirmesinin yapıldı̆̆ bu araştırma sonucunda elde edilecek bulgu ve sonuçların, spesifik bir paylaşım sistemi penceresinden Türkiye'de paylaşım ekonomisinin değerlendirmesine ışı tutması beklenmektedir. Özetle; bu araştırmada yapılan regresyon analizi sonucunda algllanan güven, ikame yararı ve sosyal etki değişkenlerinin Uber kullanma niyeti üzerinde etkisi olduğu belirlenmiştir.
\end{abstract}

\section{ABSTRACT}


Keywords:

Sharing economy, Turkey, Uber, sharing intention, trust

JEL Classification Codes: A14, D12, M10, M31
Along with AirBnb, Uber platform that one of the flagships of sharing economy which its effect is growing day by day in recent years, is in many scientific researches with the aim of analysis of sharing economy and media tools with regard to actions / business models. Uber that operates in a limited area of activity in Turkey, is sometimes exposed to reactions of taxi drivers or chambers of taxi due to led to unfair competition. Leaving aside the discussion of "who is right? Taxi drivers or Uber, we examined the opinions of users / potential users of Uber platform. In brief, this study determines the individuals' behavior (using) intention about Uber and effects of trust, existing sharing behaviors, social effect and expected benefits on Uber using intention. From this point, data is collected with Internet-based survey and it is defined the consumer-oriented view of Uber platform. Findings and results of the study that investigate sharing economy from window of a digital platform is expected to set light to reviews of sharing economy in Turkey. In summary, as a result of the regression analysis, it was determined that the perceived trust, substitution benefit and social impact variables had an effect on the intention to use Uber.

\section{GİRIŞ}

Asırlardır var olan tüketici davranışlarının yeni internet teknolojilerinin lansmanıyla birlikte yavaş yavaş değişim gösterdiği gözlenmektedir. Diğer taraftan, var olan tüketici davranışlarının değişimiyle birlikte, işletmeler ve girişimciler eko-sisteminde de var olan iş modellerinin sorgulanarak, yenilikçi iş modelleri geliştirme üzerinde yoğun çabalara girişildiği görünmektedir. Hemen her iş kolunda, gereksinim ve isteklerini karşılamaya çalışan tüketici kitlesine, var olan seçeneklere cazip alternatifler yaratabilmek için yeni yollar arayışında bulunan yeni nesil ekonomik sistem olan paylaşım ekonomisi, dijitalleşen dünyada ticari eylemlerin dönüşümüne büyük ölçüde hız kazandırmıştır. Bu noktadan hareketle; bu ekonomide faaliyet gösteren dijital işletmelerin, geleneksel işletmelere yıkıcı ve dönüştürücü etkilerde bulunan rakipler olarak pazara girmesiyle, yeni sistemin yavaş yavaş tartışmaya başlandığı gözlenmiştir. Yeni nesil dijital ekonominin önemli oyuncularından biri olarak gösterilen Uber platformuna yönelik tüketici algılarının değerlendirmesinin yapıldığı bu çalışma, spesifik bir paylaşım sistemi özelinden paylaşım ekonomisini çözümleme sürecine destek olma amacını taşımaktadır.

Tüketicilerine birbirinden farklı alternatifler sunmak için her an yenileri pazara sürülen ve tüm dünyada yoğun bir şekilde benimsenen dijital platformlar, geleneksel ticari faaliyette bulunan işletmelerin ve yasal kurum / kuruluşların dikkatini çekmektedir. Gri bir ekonomik sistem olarak gösterilen paylaşım ekonomisinin, yasal zeminin tam oturtulamamış olması ve onlarca yıldır (kimi sektörlerde yüzlerce yıldır) süregelen geleneksel sektörleri / iş modellerini bir çırpıda yıkabilme potansiyeli taşıması, söz konusu paydaşların var olan endişelerin oldukça yerinde olduğunu gözler önüne sermektedir. Ancak bu çalışmada, dijital bir taksi hizmeti platformunun yalnızca tüketici yönlü değerlendirmesi yapılmakta, dolayısıyla ticari rekabetteki konumu ve kamu kurumlarına karşı yasal sorumlulukları değerlendirmeye alınmamaktadır. Nitekim bu araştırmada; ilgili yazın incelenerek derlenen anket formu, İnternet anketi tekniğiyle katılımcılara uygulanması sonucunda araştırmanın katılımcılarından elde edilen verilerin istatistik programı ile analiz edilmekte ve elde edilen bulgular tartışılmaktadır. 


\section{UBER GİRIŞIIMI HAKKINDA}

2009 yllında ABD'de faaliyete geçen ve yeni ekonomik sistemin ilk örneklerinden biri olarak kabul edilen Uber, yeni nesil taksi hizmeti sağlayan bir işletmedir. Taksi hizmetinin yanı sıra Ubet eats ile yemek, Uber Freight. ile de yük taşımacılığı hizmeti vermekte (Li, 2020) olan Uber, 70 milyar dolar düzeyindeki piyasa değeriyle, benzer rakiplerinin arasından sıyrılarak (en yakın rakibi Lyft'in piyasa değerinin yaklaşık 15 milyar dolar olduğu düşünülürse) ön plana çıkmaktadır. Geleneksel taksi hizmeti sağlayıcılarının sunduğu hizmetlerinden fazlasını sunmayı hedefleyen Uber, çok sayıda bilgi sistemi kullanımını da içeren dijital bir işletmedir. Uber, zaman zaman 70 milyon doları aşan bir değere sahip olmasıly beraber sadece dünyanın en değerli start-up şirketi olarak tanınmakla kalmayıp, bunun yanı sıra Honda, Ford ve GM şirketleri ile karşılaştırılabilir bir konuma gelmektedir [1]. Kullanıcılarına mobil uygulama ya da internet sitesi aracılı̆̆ıla hizmet veren bu sistem, sağlanan her bir taksi hizmeti için aldığı komisyonlarla çı̆̆ gibi büyümekte ve gelecek projeksiyonu yapan Goldman Sachs ve Morgan Stanley bankaları tarafından yapılan değerlendirmeler sonucunda 120 milyar dolarlık piyasa değeri hesaplamaları yapılmaktadır. Sunduğu hizmetlerden yararlanan müşterilerinden aldığı komisyonun yanı sıra ayrıca, hizmet sağlayıcılarından da (taksi sürücüleri) sisteme giriş için aldığ üyelik ücretinin de bulunduğu gözden kaçırılmamalıdır. Seyir ya da rota belirleme sistemleri (navigasyon) kullanılması nedeniyle, bu işletmeden hizmet almak isteyen müşteriler ile hizmet sağlayıcıların birbirlerinin konumlarını hızla belirlemelerine olanak sağlanması, aynı rotayı izleyerek benzer varış noktalarına ulaşacak bireysel müşterilerin diğer müş̧erilerle ortaklaşa hizmet alabilmesine olanak tanınması, alınacak hizmetin bedelinin önceden öğrenilebilerek sürprizlerin önlenebiliyor olması, taksi geliş süresi ve yolculuk süresinin bilinebilmesi, taksi hizmeti sağlayacak sürücülerin kimliklerini görüntülü olarak incelenebilmesi, kredi kartıyla ödeme yapılıyor olması nedeniyle hizmet bedelinin kayıt altına alınabilmesi, hizmet alınacak araç türlerinin seçilebilmesi ve genellikle geleneksel taksi hizmeti sağlayıcılarından daha ekonomik hizmet sağlanabilmesi bu işletmeyi ön plana çıkarmaktadır.

Buraya kadar verilen üstün özelliklerine karşın; ulusal basında "uluslararası terör örgütlerinin maşası", "ulusal güvenliğimize tehdit", "yasadışı-korsan" faaliyeti yaygınlaştıran bir işletme olarak suçlanan Uber'in web sitesine ve mobil uygulamalarına erişimin engellenmesi ve faaliyetlerinin sonlandırılması için tepkiler yöneltilmektedir. Bunların yanı sıra Uber, kişisel bilgilere erişim konusunda da eleştirilere maruz kalmaktadır ki bu konuda Uber yöneticileri, sistemde yaklaşı 57 milyon müşteri ve 600,000 kadar Uber sürücüsünü etkileyen bir veri ihlalinin olduğunu tespit etmiştir (Rasalam ve Elson, 2019). Ayrıca trafik ekipleri tarafından yapılan sık denetimlerle hizmet sağlayıcılarına yüklü tutarlarda cezalar kesilmektedir. Bunlara ek olarak, Türkiye Cumhuriyeti Ulaştırma ve Altyapı Bakanlığı'nın Uber ve benzeri dijital taksi platformları üzerinde yaptığı incelemeler sonucunda 25 Mayıs 2018 tarihinde Karayolu Taşıma Yönetmeliği'nin 30. maddesinin 4. fikrasının değişikliğe gidilmiş ve bu tür taksi platformlarının faaliyetleri üzerinde yeni yaptırımlar getirilmiştir. Sonraki dönemlerde taksiciler tarafindan haksız rekabet oluşturduğu gerekçesiyle açılan davalarla beraber Türkiye'deki UberXL faaliyetleri durdurulmuş, sarı taksi ve turkuaz taksi faaliyetlerinin devam etmesi yönünde karar verilmiştir. Ancak davanın taksicilerin lehine sonuçlanması üzerine 21 Aralık 2019 itibari ile de Uber'in Türkiye'deki uygulamalarına erişim engeli getirilmiştir. Uber'e yöneltilen bu tepkiler, yalnızca Türkiye topraklarında sınırlı değildir. Dünyanın pek çok noktasında sürücülerinin darp edilmesi, sokak gösterilerinin düzenlenmesi, sosyal medya kampanyalarının oluşturulması gibi çok sayıda protestonun hedefi olan ve 
ülkemizde kısıtlı bir alanda faaliyet gösteren Uber, halen dünyada 80 ülkenin üzerinde yaklaşık 800 şehirde hizmetlerini sürdürmektedir.

Çin ve Rusya gibi ülkelerde rekabetin şiddetinin yüksek olması nedeniyle şirket birleşmesi yoluna giden Uber, Avrupa'da Danimarka ve Macaristan'ın da arasında bulunduğu pek çok ülkede de yasaklamalarla karşı karşıya gelmiş, müşterilerinin güvenliğini yeterince sağlayamadığı gerekçesiyle 2019 yılında İngiltere'de faaliyet izni iptal edilmiştir. Aynı yıl Almanya'da yasal gereklilikleri taşımaması nedeniyle faaliyetleri durdurulmuştur.

Her geçen gün kapsamını genişleten bu dijital platforma yöneltilen eleştirilere de yenileri sürekli eklenmektedir. Ayrıca Uber, birçok konuda (haksız rekabet, istihdam, sigorta, vergilendirme, güvenlik ve hesap verebilirlik vb.) protesto ve davayı da beraberinde getirmiştir (Borowiak, 2019). Bu noktada Uber'e yöneltilen eleştirilerin haklı yönlerine bakıldığında; ülkemizde yerleşik bir işletme olmaması nedeniyle ulusal vergilendirme sistemine tabi olmaması, tüm vergilerini ve yasal yükümlülüklerini yerine getiren geleneksel taksi hizmeti sağlayıcılarına ticari kayıplar verdirmesi, taksi hizmet alınması esnasında yaşanabilecek kusurlu ya da adli olaylarda doğrudan muhatap alınması konusunda sorunlar oluşması, hizmet sağlayıcılarının ulusal mesleki standartlar ve sahip olunması gereken belgeler konusunda yetersiz kalabilmesi ilk akla gelenlerdir.

Aslında Uber ve benzeri (Lyft, Gett, ViaandJuno, LibreTaxi) yeni nesil taksi hizmeti sunan dijital platformları eleştirmeye geçmeden önce şu soruların sorulmasında yarar vardır: Neden bu tür şirketlere gereksinim duyuldu? Geleneksel taksi hizmeti sağlayıcılarının hangi eksiklikleri ya da yanlışları bu platformların çıkışını beraberinde getirdi? Neden bu özel ulaşım hizmeti sunan dijital platformları, müşteriler tarafından yoğun bir benimsenme ile karşılandı? Bu sorular daha da arttırılabilir ancak bu sorulara verilecek yanıt, Uber ve benzeri dijital taksi platformlarının birer "sonuç" olduğu, dolayısıyla nedenlere odaklanması gerektiği üzerindedir. Tüm dünyada, özellikle turistik seyahat gerçekleştiren ve o yöreden olmadığ kolaylıkla belirlenebilen "savunmasız müşteri" kitlesine (taksi sürücülerinin bir bölümü tarafından) fahiş fiyatlarla ve görece düşük düzeydeki hizmet kalitesiyle taksi hizmeti sunuluyor olması nedeniyle, müşterilerin geleneksel taksi hizmetlerinden memnuniyet düzeyinin düşük olması, bu dijital platformlara geçişin temel nedeni olarak değerlendirilebilmektedir. Nitekim geleneksel sektörün yaşadığı sorunları çözme uğraşında olan Uber platformunda müşterilerin taksi hizmeti sağlayıcılarını puanlayarak değerlendirmelerine olanak sağlanmaktadır. Uber ve benzeri dijital taksi platformlarına eleştiriler yönelten geleneksel taksi hizmeti sağlayıcılarının, neredeyse bir asırdır kendini güncellemeden ya da çağın gereklerine göre dönüştürmeden hep aynı hizmeti sürdürmek yerine öncelikle kendi hizmetlerini ve özellikle var olan iş modellerini güncelleme yoluna gitmeleri gerekmektedir. İnsanlar, insanların davranışları (sosyolojik ve psikolojik açıdan), insanların toplumsal kabulleri, ekonomik sistemler, teknoloji, müşterilerin bir hizmetten beklentileri sürekli değişim gösterirken, geleneksel taksi hizmeti sağlayıcılarının bu değişimleri izlememeleri sonucu, yenilikçi iş modellerine dayalı yeni rakiplerle yakın gelecekte de karşılaşmaları olasıdır. Çünkü dünya hızla değişmekte, yüzyıllardır var olan iş modelleri sorgulanmakta ve yaşanan teknoloji devrimi tüm paydaşlara yepyeni davranış kalıpları getirmektedir. Kişi (2018) tarafından Uber platformu üzerine yapılan incelemeler sonucunda, yeni ekonomik sistemin paydaşlarına şu üç yol haritası önerilmektedir: Bunlar; Uber'in faaliyetlerini durdurmasını sağlamak, Uber'in mobil uygulama ve web sitesine 
erişimin tümüyle engellenmesini temin etmek ve tüm dünyada uygulanan bu iş modelinin ülkemizde başarıyla yürütülebilmesi için var olan engelleri ortadan kaldırmaktır.

\section{LITERATÜR ANALİZi}

Dijital platformlar aracılığıyla atıl (boş) durumdaki kaynakların paylaşımlı kullanılarak ekonomiye kazandırılmasını amaçlayan bir sistem olarak tanımlanabilecek paylaşım ekonomisi, (Kişi, 2018:64) konusunda yapılan araştırmaların son yıllarda hız kazandığ görülmektedir. Uber'in ait olduğu bu yeni ekonomik düzenin kavramsal incelemesinin ve teorik altyapısının incelendiği araştırmaların (Belk, 2007, 2010, 2014; Ertz vd., 2016a, 2016b, 2017) yanı sıra, bu ekonomide yer alan oyuncuların davranışlarını ve davranışlarının ardında yatan nedenleri ortaya koyan pek çok araştırmanın (Hellwig vd., 2015; Böckler ve Meelen, 2016; Bucher vd., 2016; Hwang ve Griffiths, 2017; Roos ve Hahn, 2017) yapıldığ1 gözlenmektedir. Sektörel bazda yapılan çalışmalara bakıldığında ise; konaklama sektörü (Tussyadiah, 2015) tarım sektörü (Miralles vd., 2017), otomobil paylaşımı (Çabuk vd., 2015; Barnes ve Mattsson, 2017), oyuncak kütüphanesi (Ozanne ve Ballantine, 2010), giyim sektörü (Park ve Armstrong, 2016), giysi kütüphaneleri (Pedersen ve Netter, 2015), cep telefonu süre paylaşımı ve bisiklet paylaşımı (Lamberton ve Rose, 2012), otomobil paylaşımı, çamaşır yıkama hizmetleri ve elektrikli aletler (Mont, 2004) konusunda yapılan çalışmalar ilk göze çarpanlardır. Spesifik paylaşım platroformları olan Ecomodo (Piscicelli vd., 2015), ReallyReallyFreeMarkets (Albinsson ve Perera, 2012), car2go ve AirBnb (Möhlmann, 2015), Zipcar (Bardhi ve Eckhardt, 2012) ve Uber (Cannon ve Summers, 2014; Rauch ve Schleicher, 2015; Wallsten, 2015; Cramer ve Krueger, 2016; Dreyer vd., 2017, Rogers, 2017; Kişi, 2018) özelinde yapılan çalışmaların ise oldukça az sayıda olduğunu ifade etmek mümkündür. Pek çok kişi tarafından yapılan değerlendirmelerde, AirBnb ile birlikte paylaşım ekonomisinin öncü platformları olarak nitelendirilen Uber platformuna yönelik yapılan ulusal ve uluslararası araştırmaların oldukça az olduğu göze çarpmaktadır. Söz gelimi Google Akademik veri tabanında "AirBnb" özelinde tarama yapıldığında sayfalarca sonuca rastlamak mümkünken, Uber özelinde çok az çalışmanın yapıldığı karşımıza çıkmaktadır. Aslında, paylaşım platformları içerisindeki konumu doğrultusunda Uber'ın günümüz ekonomik düzeninde yaşanan değişimdeki payının büyük olduğunu belirtmekte fayda vardır (Tzur, 2019). Ülkemizde Uber platformu hakkında yapılan bilimsel araştırmalara göz atıldığında; Kişi (2018) tarafından yapılan kavramsal inceleme dışında başka bir araştırma yapılmadığı kolaylıkla ön plana çıkmaktadır. Bu bağlamda, yapılan araştırmanın Uber'in kullanıcı profilini ortaya koymaya yönelik yapılan ilk araştırma olduğunu ifade edebilmek mümkündür.

\section{ARAŞTIRMANIN YÖNTEMI}

Taksici mi Uber mi kim haklı? tartışmasında bir taraf olmayı seçmek yerine, ülkemizde de yasal niteliği tartışmalı olan Uber platformunun kullanıcıları / potansiyel kullanıcıların yaklaşımlarını ortaya koymak bu araştırmanın amacını oluşturmaktadır. Bir başka deyişle, bu sistemi kullanmış olan veya Uber platformunun kendi yerleşim yerlerinde faaliyet göstermemesi nedeniyle şu anda bu sistemin kullanıcısı olmayan bireylerin, kendi il ve ilçelerinde faaliyete geçmesi durumunda sergileyebilecekleri davranışları ve bu davranışlar üzerinde etkisi olabilecek faktörleri ortaya koymak bu araştırmada amaçlanmaktadır. $\mathrm{Bu}$ noktadan hareketle internet ortamında yapılan anket çalışmasıyla; sosyal etki, güven, var olan paylaşım davranışları ve beklenen yarar türlerinin (ekonomik, sosyal, anti-endüstri, eğlence ve ikame yararı) Uber platformunu kullanma ve kullanımını tavsiye etme niyeti üzerindeki 
olası etkileri incelenmektedir. Ülkemizde son yıllarda tartışma konusu olan Uber platformunun tüketici yönlü değerlendirmesinin yapıldığ edilecek bulgu ve sonuçların, spesifik bir paylaşım platformu penceresinden Türkiye'de paylaşım ekonomisinin değerlendirmesine 1 şık tutması beklenmektedir. Araştırmanın modeli Şekil 1'de gösterilmektedir.

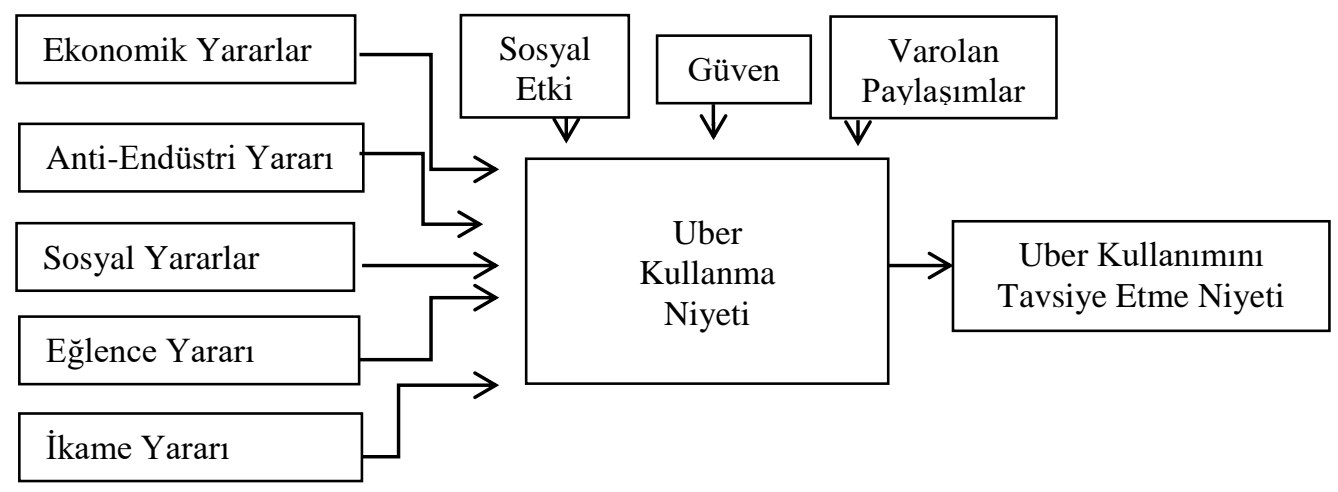

Şekil 1. Araştırmanın Modeli

Araştırmanın hipotezleri ise şunlardır:

H1: Ekonomik yararlar, Uber platformunu kullanma niyeti üzerinde etkilidir.

H2: Anti-endüstri yarar1, Uber platformunu kullanma niyeti üzerinde etkilidir.

H3: Sosyal yararlar, Uber platformunu kullanma niyeti üzerinde etkilidir.

H4: Eğlence yararı, Uber platformunu kullanma niyeti üzerinde etkilidir.

H5: İkame yararı, Uber platformunu kullanma niyeti üzerinde etkilidir.

H6: Sosyal etki, Uber platformunu kullanma niyeti üzerinde etkilidir.

H7: Algılanan güven, Uber platformunu kullanma niyeti üzerinde etkilidir.

H8: Verici rolündeki iç paylaşım davranışları, Uber platformunu kullanma niyeti üzerinde etkilidir.

H9: Alıcı rolündeki iç paylaşım davranışları, Uber platformunu kullanma niyeti üzerinde etkilidir.

$\mathrm{Bu}$ araştırmada veri toplama tekniği olarak kullanılan anket formunun oluşturulmasında literatürde yer alan çalışmalardan yararlanarak on ölçekten yararlanılmıştır. Bir başka deyişle on ayrı ölçeğin derlendiği bir soru formu oluşturulmuştur. Bu ölçekler; bireylerin var olan paylaşım davranışları ölçeği (Barnes ve Mattson, 2017); bireylerin Uber platformunu tercih etme / kullanma niyetleri ölçeği (Bhattacherjee ve Premkumar, 2004), bireylerin Uber platformunu kullanmayı çevresine tavsiye etme niyeti ölçeği (Maxham ve Netemeyer 430 
(2002)'den uyarlayan Barnes ve Mattson, 2017), bireylerin Uber platformuna ilişkin güven algıları ölçeği (Pizzol vd., 2017), güven algıları ölçeği-2 (Barnes ve Mattson, 2017), bireylerin algıladığı sosyal etki ölçeği (Hsu ve Lin, 2008; Venkatesh ve Davis, 2000), algılanan ekonomik yararlar ölçeği (Tussyadiah, 2015), algılanan anti-endüstri yararı ölçeği (Lamberton ve Rose, 2012), algılanan sosyal yarar ölçeği (Lamberton ve Rose, 2012), algılanan eğlence yararı ölçeği (Hsu ve Lin, 2008) ve algılanan ikame yararı ölçeğidir (Lamberton ve Rose, 2012). Anket formunda bu ölçeklerin yanı sıra, katılımcıların taksiye biniş sıklığı, daha önce Uber platformunu kullanıp kullanmadıkları, katılımcıların cinsiyetleri ve yaş gruplarını öğrenmeye yönelik sorular yer almaktadır. Son olarak, bu araştırmada kolayda örneklem yöntemiyle belirlenen 294 katılımcıdan veriler toplanmış ve bu veriler analiz edilmiştir. Araştırma modelinin test edilmesinde çoklu regresyon analizi yapılmıştır.

\section{ARAŞTIRMANIN BULGULARI}

Araştırma katılımcılarına ilişkin karakteristik ilk bulgular tablo 1'de sunulmaktadır. Bu tabloda, araştırmaya katılan 294 bireyin \%23.1'inin daha önce Uber kullanmış bireyler iken; katılımcıların \%76.9'unun daha önce Uber platformundan hizmet almamış bireylerden oluştuğu gözlenmektedir. Bu bulgu, araştırma yürütülen katılımcıların önemli bölümünün doğrudan Uber deneyimi yaşamaksızın fikirlerini bu araştırmada paylaştıklarını yansıtmaktadır. Katılımcıların cinsiyete göre dağılımlarına bakıldığında; neredeyse yarı yarıya (\%49.7 - \%50.3 ) temsil edildikleri ortaya çıkmaktadır. Katılımcıların yaş dağılımları incelendiğinde, 18-45 yaş arası katılımcıların örneklemin \%93.5'ini oluşturduğu görülmektedir. Yenilikçi bir iş modelini uygulayan görece yeni bir işletmeye dair bu araştırmada genç/orta yaş gruplarının görüşlerinin ağırlıklı olarak alınmış olması önemlidir.

Tablo 1. Araştırmada Elde Edilen Betimsel İstatistik Bulguları

\begin{tabular}{|c|c|c|c|c|c|}
\hline Cinsiyet & f & $\%$ & $\begin{array}{l}\text { Yaş } \\
\text { Grupları }\end{array}$ & f & $\%$ \\
\hline Kadın & 146 & 49.7 & $0-17$ & 2 & 0.7 \\
\hline Erkek & 148 & 50.3 & $18-25$ & 99 & 33.7 \\
\hline Toplam & 294 & 100 & 26-35 & 137 & 46.6 \\
\hline & & & $36-45$ & 39 & 13.3 \\
\hline $\begin{array}{l}\text { Uber } \\
\text { Kullandınız } \\
\text { mı? }\end{array}$ & $\mathrm{f}$ & $\%$ & $46-55$ & 14 & 4.8 \\
\hline Evet & 68 & 23.1 & $56-65$ & 3 & 1.0 \\
\hline Hayır & 226 & 76.9 & $65+$ & - & - \\
\hline Toplam & 294 & 100 & Toplam & 294 & 100 \\
\hline
\end{tabular}

Araştırmada yer alan ölçekler öncelikle faktör analizine tabi tutulmuş ve özet bulguları ekler (ek1) bölümünde verilmiştir. Faktör analizi sonucunda, ölçeklere ilişkin aritmetik ortalama değerleri tablo 2'de sunulmaktadır. Bu tabloya göz atıldığında; katılımcıların taksi kullanım sıklığının yüksek bir ortalama değerine sahip olmadığı görülmektedir. Bu bulguya dayanarak, bu araştırmada ağırlıklı olarak ara sıra veya seyrek taksi kullanan bir katılımcı grubunun, bu hizmetin alternatifi konumunda bulunan bir dijital platform hakkında görüşlerinin alındığı ifade edilebilmektedir. Bu bulgunun yanı sıra, katılımcıların Uber'in sunduğu yarar türlerine göre dağılımları incelendiğinde; yüksekten düşüğe doğru sırasıyla ikame yararı, eğlence yararı, ekonomik yarar, sosyal yararlar ve anti-endüstri yararının algılandığı gözlenmektedir. 
Son olarak; katılımcıların yakın çevresiyle yaptığı paylaşımlara (verici ve alıcı rolü ayrı ayrı incelenerek) ilişkin bulgular incelendiğinde; alıcı rolün oldukça düşük aritmetik ortalama değerine sahip olduğu gözlenmiştir. Uber platformunu kullanma niyeti ve Uber platformu kullanımını başkalarına önerme niyetine ilişkin aritmetik ortalama değerleri incelendiğinde ise, bu üç değişken içerisinde var olan paylaşım değişkeninin en düşük ortalama değerine sahip olduğu ortaya çıkmaktadır. Bir başka deyişle, katılımcıların Uber'i kullanma niyetleri ( $\overline{\mathrm{x}}$ : 4.06) ve Uber kullanımını tavsiye etme niyetleri ( $\overline{\mathrm{x}}$ : 3.09) ile karşılaştırıldığında, var olan paylaşım davranışlarının düşük düzeyde ( $\mathrm{x}: 2.97)$ kaldığı gözlenmiştir.

Tablo 2. Araştırma Ölçeklerine Göre Oluşan Ortalama Değerleri

\begin{tabular}{|l|l|l|l|l|l|l|}
\hline Ölçek & A.O. & S.S. & & & A.O. & S.S. \\
\hline Uber Kullanma Niyeti & 4.06 & 1.01 & & Güven & 3.63 & 0.98 \\
\hline İkame Yararı & 4.06 & 0.96 & Sosyal Etki & 3.54 & 1.14 \\
\hline Eğlence Yararı & 3.89 & 1.00 & & Anti-endüstri Yararı & 3.54 & 1.18 \\
\hline Ekonomik Yararlar & 3.78 & 0.99 & & Uber Tavsiye Niyeti & 3.09 & 1.02 \\
\hline Verici (İç) Paylaşımlar & 3.71 & 0.92 & Alıcı (İç) Paylaşımlar & 2.24 & 1.01 \\
\hline Sosyal Yararlar & 3.64 & 0.95 & Taksi Biniş Sıklığ1 & 2.78 & 1.33 \\
\hline * Tüm Ölçekler için Cronbach Alpha Katsayısı > .70 & \\
** A.O.: Aritmetik Ortalama; S.S.: Standart Sapma \\
\hline
\end{tabular}

Betimsel istatistik bulgularının ardından, öncelikle Pearson korelasyon analizi yapılmış ve bu analizin bulguları ekler (ek2) bölümünde sunulmuştur. Korelasyon analizi sonrasında ise, tasarlanan araştırma modelini test etmek amacıyla; varolan alıcı rolündeki iç paylaşım, verici rolündeki iç paylaşım, algılanan yararlar (ekonomik, anti-endüstri, sosyal, eğlence ve ikame yararı), hissedilen güven düzeyi ve sosyal etkinin Uber platformunu kullanma niyeti ve tavsiye etme niyeti üzerindeki olası etkilerini belirlemek amacıyla çoklu doğrusal regresyon analizi yapılmıştır. Yapılan regresyon analizi sonucunda; Uber'e karşı hissedilen güven düzeyi, algılanan ikame yararı ve sosyal etkinin Uber platfomunu kullanma niyeti üzerinde etkili olduğu ortaya çıkmıştır $(\mathrm{p}<0.01)$. Böylece, araştırmanın H5, H6 ve H7 isimli hipotezleri kabul edilmiştir. Ayrıca, Uber platformunun kullanma niyetini en fazla etkileyen değişkenin "Uber platformuna karşı duyulan güven" olması, katılımcıların özel ulaşım hizmeti alıcısı olarak öncelikle güvene dayalı bir hizmet alma arayışında olduğunu yansıtmaktadır. Bu platformun kullanıcılarına karşı zaman zaman dile getirilen "ekonomik olduğu için tercih ediyorlar" şeklindeki iddianın bu araştırmada ispatlanamadığını, bu yönüyle bu araştırma için "temelsiz iddialar" arasında kaldığını yansıtmaktadır. Ayrıca, algılanan güven değişkeninin ardından "algılanan ikame yarar" değişkeninin bu platformu kullanma niyeti üzerinde anlamlı düzeyde etkili olduğunun ortaya çıkması kısaca yorumlanacak olursa; katılımcıların Uber platformu aracılığıyla aldıkları özel ulaşım hizmetini geleneksel taksilerden aldıkları hizmetin birebir ikamesi olarak değerlendirdiklerini ifade etmektedir. Bir başka deyişle, gelenekel taksi hizmetinin ikamesi olarak görülmesinin, Uber kullanma niyetini etkilediği belirtilmektedir. $\mathrm{Bu}$ analizde diğer bir değişken olan "sosyal etki" değişkeninin kullanma niyeti üzerinde (diğer iki değişkene göre daha düşük düzeyde olsa da) etkili olduğu sonucu değerlendirilecek olursa; katılımcıların yakın çevresindeki bireylerin Uber kullanımı konusunda özendirici görüşlerde bulunmalarının katılımcıların Uber platformundan hizmet alma niyetini olumlu yönde etkilediği ortaya çıkmaktadır.

Tablo 3. Regresyon Analizine İlişsin Bulgular ve Test Sonuçları (1) 


\begin{tabular}{|c|c|c|c|c|c|c|}
\hline \multicolumn{7}{|c|}{$\begin{array}{l}\text { Belirli Faktörlerin Uber Kullanma Niyeti Üzerindeki Etkilerini Ortaya Koymaya Yönelik } \\
\text { Coklu Regresyon Analizi Bulguları }\end{array}$} \\
\hline Model & $\mathbf{R}$ & $\mathbf{R}^{2}$ & S.H. & $\mathbf{F}$ & $\mathbf{P}$ & D-W \\
\hline 1 & 0.715 & 0.512 & 0.715 & 297.686 & 0.000 & \multirow{2}{*}{2.028} \\
\hline 2 & 0.771 & 0.595 & 0.652 & 208.036 & 0.000 & \\
\hline 3 & 0.777 & 0.603 & 0.647 & 142.993 & 0.000 & \\
\hline \multicolumn{2}{|l|}{ Model } & B & S.H. & Beta & $\mathbf{t}$ & $\mathbf{P}$ \\
\hline \multirow{2}{*}{1} & Sabit Terim & 1.353 & 0.162 & - & 8.366 & 0.000 \\
\hline & Güven & 0.745 & 0.043 & 0.715 & 17.254 & 0.000 \\
\hline \multirow{3}{*}{2} & Sabit Terim & 0.653 & 0.174 & - & 3.760 & 0.000 \\
\hline & Güven & 0.491 & 0.052 & 0.472 & 9.530 & 0.000 \\
\hline & İkame Yarar & 0.400 & 0.052 & 0.378 & 7.636 & 0.000 \\
\hline \multirow{4}{*}{3} & Sabit Terim & 0.611 & 0.173 & - & 3.527 & 0.000 \\
\hline & Güven & 0.432 & 0.057 & 0.415 & 7.627 & 0.000 \\
\hline & İkame Yarar & 0.370 & 0.053 & 0.350 & 6.938 & 0.000 \\
\hline & Sosyal Etki & 0.107 & 0.044 & 0.119 & 2.413 & 0.016 \\
\hline \multicolumn{7}{|c|}{$\begin{array}{l}\text { Uber Kullanma Niyetinin Uber Kullanımını Tavsiye Etme Niyeti Üzerindeki Etkilerini } \\
\text { Ortaya Koymaya Yönelik Regresyon Analizi Bulguları }\end{array}$} \\
\hline Model & $\mathbf{R}$ & $\mathbf{R}^{2}$ & S.H. & $\mathbf{F}$ & $\mathbf{P}$ & D-W \\
\hline 1 & 0.863 & 0.745 & 0.518 & 851.997 & 0.000 & 1.852 \\
\hline Model & & B & S.H. & Beta & $t$ & $\mathbf{P}$ \\
\hline \multirow{2}{*}{1} & Sabit Terim & 0.412 & 0.125 & - & 3.308 & 0.001 \\
\hline & UK niyeti & 0.868 & 0.030 & 0.863 & 29.189 & 0.000 \\
\hline
\end{tabular}

(S.H.: Standart Hata D.W.:Durbin-Watson)

Araştırma modelinde yer alan sekiz değişkenin Uber kullanma niyeti üzerindeki etkilerinin analiz edilmesinin ardından, Uber kullanma niyetinin Uber kullanımını tavsiye etme niyeti üzerindeki etkileri analiz edilmiştir. Yapılan regresyon analizi bulguları tablo 3'ün alt kısmında gösterilmektedir. Söz konusu analiz sonucunda, oldukça yüksek bir r2 değeriyle yansıtılan bulgulara göre Uber kullanma niyetinin Uber kullanımını tavsiye etme niyeti üzerinde oldukça belirleyici olduğu belirlenmiştir.

Tablo 4. Regresyon Analizine İlişkin Bulgular ve Test Sonuçları (2)

\section{Belirli Faktörlerin Uber Kullanımını Tavsiye Etme Niyeti Üzerindeki Etkilerini Ortaya} Koymaya Yönelik Çoklu Regresyon Analizi Bulguları 


\begin{tabular}{|c|c|c|c|c|c|c|}
\hline Model & $\mathbf{R}$ & $\mathbf{R}^{2}$ & S.H. & $\mathbf{F}$ & $\mathbf{P}$ & D-W \\
\hline 1 & 0.861 & 0.742 & 0.523 & 814.906 & 0.000 & \multirow{3}{*}{1.888} \\
\hline 2 & 0.894 & 0.799 & 0.462 & 561.186 & 0.000 & \\
\hline 3 & 0.897 & 0.804 & 0.457 & 386.252 & 0.000 & \\
\hline Model & & B & S.H. & Beta & $\mathbf{t}$ & $\mathbf{P}$ \\
\hline \multirow{2}{*}{1} & Sabit Terim & 0.420 & 0.127 & - & 3.315 & 0.001 \\
\hline & UK niyeti & 0.866 & 0.030 & 0.861 & 28.547 & 0.000 \\
\hline \multirow{3}{*}{2} & Sabit Terim & 0.120 & 0.117 & - & 1.031 & 0.030 \\
\hline & UK niyeti & 0.620 & 0.038 & 0.617 & 16.151 & 0.000 \\
\hline & Güven & 0.358 & 0.040 & 0.342 & 8.956 & 0.000 \\
\hline \multirow{4}{*}{3} & Sabit Terim & 0.014 & 0.125 & - & 0.114 & 0.090 \\
\hline & UK niyeti & 0.571 & 0.042 & 0.568 & 13.712 & 0.000 \\
\hline & Güven & 0.322 & 0.041 & 0.307 & 7.753 & 0.000 \\
\hline & İkame yarar & 0.115 & 0.040 & 0.108 & 2.850 & 0.005 \\
\hline
\end{tabular}

Araştırma modelinin test edilmesi için yapılan regresyon analizinin ardından, araştırma modelinde yansıtılmamış olsa da (araştırma modelinin tasarlanmasında göz önünde tutulmamış olsa da), sekiz temel değişken ve Uber kullanma niyeti değişkeninin doğrudan Uber kullanımını tavsiye etme niyeti üzerindeki etkileri yapılan regresyon analizi ile incelenmiştir. Analiz bulguları tablo Elde edilen bulgulara göre, Uber kullanma niyeti değişkeninin, Uber kullanımını tavsiye etme niyeti üzerinde en fazla etkili değişken olduğu ortaya çıkmıştır. Daha önce tek bağımsız değişken olarak tavsiye etme niyeti üzerindeki etkileri analiz edilen bu değişkeni bir kenara bırakacak olursak (önceki paragrafta bu konuda gerekli açıklama yapıldığı için); algılanan güven ve ikame yarar değişkeninin Uber kullanımını tavsiye etme niyeti üzerinde etkili olduğu belirlenen diğer değişkenler olduğu belirlenmiştir. Hatırlatmakta yarar var; bu iki değişkenin daha önce Uber kullanma niyeti üzerinde de doğrudan etkili olduğu belirlenmişti.

\section{SONUÇ VE ÖNERILER}

Ortaklaşa tüketim hareketinin ve paylaşım ekonomisinin çı̆̆ gibi büyümesine paralel olarak çok sayıda kar amaçlı ya da kar amaçlı olmayan girişimin doğmasına yol açmıştır. AirBnb ile bu yeni ekonominin iki lokomotifinden biri olarak görülen Uber, coğrafik bilgi sistemi tabanlı ve internet teknolojilerini kullanan yeni bir taksi hizmeti platformudur. Kullanıcılarına ekonomik yararların yanı sıra pek çok yararı sunan bu platformun hem kullanıcıları hem hizmet sağlayıcıları hem de protestocuları çı̆̆ gibi artmaktadır. Bununla beraber ülkemiz özelinde geleneksel taksicilerin protestolarının arttığı dönemde bile kullanıcı sayısını yaklaşık beş kat arttırmış [2] olması, bu yeni taksi platformuna kullanıcıların oldukça olumlu tepkiler verdiğini gözler önüne sermektedir. 2009 yılında ABD'de özel taksi hizmeti ile başlayan yolculuğu yüze yakın ülkede otonom araçlarla yolculuk, deniz ulaşımında ve yemek siparişleriyle çeşitlendirme uğraşında olan Uber, AirBnb platformunun ardından paylaşım ekonomisinin ikinci önemli oyuncusu olarak görülmektedir. Ancak güncel piyasa değerleri açısından değerlendirildiğinde; son iki yılda (2018-2019) karlılığında erime olmasına rağmen yaklaşık 70 milyar dolarlık piyasa değeriyle AirBnB'nin yaklaşık iki katı piyasa değeriyle 2020 yılında faaliyetlerini sürdürmektedir. İlk yıllarda geleneksel özel ulaşım hizmetini (taksi) yakından sarsan büyüme hızı ve benimsenme oranıyla adından söz ettiren bu platform, yıllar geçtikçe artan tepkiler nedeniyle pek çok ülkede zor durumda kalarak ya faaliyetleri kısıtlanmış ya da tümüyle pazar dışı bırakılmıştır. Mobil uygulamalar ve web teknolojisi ile 
geleneksel ulaşım hizmetine aslında yeni bir soluk getiren bu platform; üye sayısı, araç kapasitesi ve sürücü sayısı artışıla birlikte özellikle İstanbul'da görünürlüğü iyice artmış ve taksi işletmecilerinin şiddete (fiziksel saldırıya) varan yoğun tepkilerine maruz kalmıştır. Paylaşım ekonomisinin mantığına uygun bir şekilde tanınmayan kullanıcılarla birlikte taksi hizmetinin ortaklaşa alınabilmesi ve ödemenin paylaşılabilmesi, yaşanan deneyimin ve hizmet sağlayıcısının puanlanabilmesi, harita uygulamaları ile varış noktasının, mesafesinin ve ücretlendirmenin keskin bir şekilde yapılabilmesi, yolculuk öncesi rezervasyon yapılabilmesi, kredi kartıyla ödeme seçeneği sunulması, farklı ulaşım araçlarından kullanıcıya seçim yapma hakkı sunması, yolculuk öncesi ödeme yapılacak tutarın öğrenilebilmesi gibi yenilikleri bu sektöre kazandırmıştır.

Bunca yeniliğe karşın, var olan sektörü derinden etkileyen büyüme eğilimi ve geleneksel taksi hizmeti işletmelerini yok etme tehdidi içermesi nedeniyle çok sayıda protestoya maruz kalmıştır. Aslında bu dijital platformun yükselişini, yüzyıllardır değişmeyen iş modeliyle işlerini yürüten bir iş kolunda teknoloji, toplumun sosyolojik yapısında ve tüketici beklentisindeki değişimi görmezden gelen geleneksel taksi hizmetinin yanlışlarında aramakta yarar vardır. Nitekim Uber platformunun başarısi; geleneksel işletmeler tarafından müşterinin saatlerce dolaştırılması, yüksek tutarda bedel istenebilmesi, standart güzergahta farklı taksi işletmelerinin iki kata varan standardı olmayan bedel istenebilmesi, konfordan uzak, eski ve yıpranmış araçlarla taksi hizmetinden yararlanmaktan memnuniyet duymayan müşteri kitlesinin varlığı ve müşteri iletişimi konusunda çok sayıda yetersiz müşteri hizmetinin sunulması gibi sıralanabilecek eksiklikleri gideren bir alternatif olmasında gizlidir.

Mesleki yeterlilik, vergilendirme, sigortasız ve yasal sürelerin üzerinde çalışma konularında yapılan eleştiriler ne kadar doğruysa; okyanus ötesinden ulusal güvenliğimize bir tehdit olarak görülmesi ve bu platformun müşterilerine görece düşük hizmet kalitesi sunduğunun dile getirilmesi o kadar yanlıştır. Diğer taraftan, Uber tarafından verilen yolcu taşımacılığı hizmetinin yasal zemine uygun hale getirilmesi için neler yapılabileceğini irdelenmeksizin bir ülke içerisinde faaliyetlerine son verilmesinin ne kadar doğru bir tepki olduğu tartışmalı bir konudur. Çünkü, bir ihtiyacı yok saymak kısa süreli bir çözümdür ve er geç o ihtiyacı giderecek yeni yeni dijital platformlar pazara girecektir.

İnternet anketi aracıllğ̆yla 294 bireyden elde edilen verilerin analiz edildiği bu araştırma, Uber hakkında Türkiye ölçeğinde yapılan ilk ampirik bilimsel çalışma niteliğini taşımaktadır. $\mathrm{Bu}$ araştırmada 294 bireyin spesifik bir paylaşım platformuna katılım niyeti incelenmiş, belirli değişkenlerin katılım niyeti ve tavsiye niyeti üzerindeki etkileri ortaya konmuş, katılımcıların var olan paylaşımları ile Uber'e katılım niyetleri arasında çok düşük düzeyde ilişki (r:.163) bulunduğu saptanmıştır. Ancak yapılan çoklu regresyon analizi sonucunda elde edilen yüksek $\mathrm{r} 2$ değerleri (katılım niyeti için .603; tavsiye niyeti için .804) bu araştırmada Uber'e katılım niyetinin önemli bir bölümünün açıklanabildiğini yansıtmaktadır. Bu araştırmanın kısıtlarını kısaca kaleme almak gerekirse; kolayda örnekleme yöntemiyle seçilen 294 bireyden veri toplanmış olması, ölçülen katılım niyetini belirleyen görece az sayıda değişkenin araştırmada yer alması, iki yönlü inceleme ve karşılaştırma yapılmamış olması (taksicilere yönelik - Uber'e yönelik davranış niyeti), Uber'de hizmet sağlayıcı rolü üstlenen birey ve kuruluşların görüşlerinin bu araştırmada yer almaması ve son olarak Uber / taksi kullanma sıklığı yüksek düzeyde olmayan bir kitlenin görüşlerinin yansıtılmış olması bu araştırmanın kısıtları arasındadır. 
Ülkemizde 100,000'e yakın taksi plakası sahibi, müşteriler ve kamu kurumlarını ilgilendiren yeni nesil bir dijital taksi platformunun incelemesinin yapıldığı bu çalışma konusunda gelecekte araştırmalar yapmayı düşünen araştırmacılar için temel öneriler şunlardır:

- Bu çalışmada tek yönlü inceleme yapılmıştır. Aslında Uber sürücüleri, taksiciler, yasa koyucular, sivil toplum kuruluşları gibi pek çok farklı kesimin görüşünün de yansıtıldığı kapsayıcı bir araştırmanın yapılması yerinde olacaktır. Spesifik inceleme yapılmak istenirse de, en az bir kez Uber deneyimini yaşamış bireyler üzerinde bir inceleme yapılması da farklı bulguları beraberinde getirebilecektir.

- Uber hakkında olumlu haberlerle ön bilgilendirmenin yer aldığ bilgilendirmenin yapıldığı ve herhangi bir ön bilgilendirme yapılmadığı durumda (manipülasyon yaklaşımı) toplanan veriler arasındaki ayrımın analiz edilebileceği çalışmaların yapılması gerekmektedir.

- Uber kullanım niyetini ya da Uber kullanımını tavsiye etme niyetini olumsuz yönde etkileyebilecek faktörlere bu araştırmada yer verilmemiştir. Gelecek araştırmalarda, hem Uber kullanımı konusunda "özendirici" nitelikte olan olumlu, hem de Uber kullanımı konusunda "engelleyici" nitelikte olan ve olumsuz yönde etkide bulunan araştırma değişkenlerinin modelde yer verilmesi önerilmektedir. Hesap verebilirlik uygulamalarının geliştirilmesi STK'ları sorumlu yönetim anlayışı çerçevesinde kaynaklarını daha verimli kullanmaya zorlayacağı gibi STK'ların arkasındaki toplumsal desteği artırarak ülkemizde sivil toplumun büyümesine ve gelişmesine katkıda bulunacaktır.

Kurulmasından yaklaşık beş yıl sonra 2014 yılında Türkiye pazarına büyük bir heyecanla giriş yapan Uber'in 2019 yılının Ekim ayında mahkeme kararıyla faaliyet izinleri sonlandırıldı ve Aralık ayında internet sitesine ve mobil uygulamalarına erişsim engellenmesiyle Türkiye pazarından tamamen çekilmiş (el çektirilmiş) oldu. Bu sondan sonrasına, bir başka deyişle araştırmanın konusunu oluşturan Uber platformunun ülkemiz topraklarındaki yakın geleceğine (2021 ve sonrasına) kısaca değinilmesinde yarar vardır. Çok sayıda olumsuz haberle anılan, belirli kesimlerin protestolarına maruz kalan ve faaliyetlerini sınırlandırmak için uğruna yasal düzenlemeler yapılan Uber, ülkemizde ve dünyada faaliyetlerini tamamen durdurursa ne olur? İhtiyaç ortadan kalkmadan ihtiyacı gideren objeleri ortadan kaldırır ya da yasaklarsanız, bu ihtiyaç yeni çözümler arar ve yeni girişimler doğar. Uber de küresel ölçekte özel taksi hizmetinden memnun olmayan ve yüksek kalitede taksi hizmeti arayan bir ihtiyacın sonucu doğan bir platformdur. Yapılan bu araştırmada "güven" değişkeninin kullanma niyetini etkilemede en belirgin faktör olarak ön plana çıktığg Uber platformunun yasaklanması ve bu ülkeden çekilmeye zorlanmasıyla, "kaybeden kesimler arasında tüketicilerin de yer aldığı söylenebilir mi?” sorusu yanıtlanmaya muhtaçtır. Paylaşım ekonomisinin ayak seslerinin ülkemizde de yavaş yavaş görüldüğü dikkate alınırsa; Uber pazardan çıksa bile, başka (ulusal / küresel) platformların pazara yakın gelecekte lanse edilmesi muhtemeldir. Önemli olan, Uber ve benzeri dijital platformların içerdikleri yasal sorunları ortadan kaldırmaya öncelik verilmesidir. Bu bağlamda; kişisel bilgilerin korunması konusunda (Uber sürücüleri, müşterilerinin adreslerine istedikleri an erişim sağlayabilmekte), vergilendirme konusunda, Türkiye sınırlarında şirketleşme olmaması konusunda, Uber faaliyetlerinin denetimi ve yetkilendirmesinde ve kişisel tüketici haklarının korunması konusundaki var olan sorunların bir an önce çözüme kavuşturulmasında yarar vardır. Nitekim, sorunlar etkin bir biçimde çözüldüğünde benzer dijital platformların da pazarda faaliyet göstermesi beklenmektedir. Söz gelimi, geleneksel taksi işletmecilerinin Uber’e Karş1 436 
‘@taksi’ uygulamasını ve İstanbul Büyükşehir Belediyesinin “itaksi” uygulamasını tanıtması; yaşanan bir değişimi ve geleneksel hizmet sağlayıcılarının bu değişime uyum sağlama amacı güden etkin adımları olarak göze çarpmakta, taksicilik sektörünün bir değişim sürecinde olduğunu kanıtlamaktadır.

\section{KAYNAKÇA}

ALBINSSON, P.A. \&Perera, B.Y. (2012). "Alternative Marketplaces in the 21 st Century: Building Community Through Sharing Events", Journal of Consumer Behavior, 11 (4): 303-315.

BARDHI, F. \&Eckhardt, G.M. (2012). "Access-Based Consumption: The Case of Car Sharing", Journal of Consumer Research, 39 (4): 881-898.

BARNES, S.J., \& MATTSSON, J. (2017). "Understanding Collaborative Consumption: Test of a Theoretical Model”, Technological Forecasting \& Social Change, 118(1):281292.

BELK, R. (2007). "Why Not Share Rather Than Own?", The Annals of the American Academy of Political and Social Science, 611 (1): 126-140.

BELK, R. (2010). "Sharing”, Journal of Consumer Research, 36(5): 715-734.

BELK, R. (2014). "You Are What You Can Access: Sharing and Collaborative Consumption Online", Journal of Business Research, 67(8): 1595-1600.

BELK, R. (2014b). "Sharing Versus Pseudo-Sharing in Web 2.0”, Anthropologist, 18(1): 723.

BHATTACHERJEE, A. \& PREMKUMAR, G. (2004). Understanding Changes in Belief and Attitude Toward Information Technology Usage: A Theoretical Model and Longitudinal Test, MIS Quarterly, 28 (2): 229-254.

BOROWIAK, C. (2019). Poverty In Transit: Uber, Taxi Coops, And The Struggle Over Philadelphia's Transportation Economy. Antipode. 51 (4): 1079-1100.

BÖCKER, L., \& MEELEN, T. (2016). "Sharing for People, Planet or Profit? Analysing Motivations For Intended Sharing Economy Participation", Innovation Studies Utrecht - (ISU) Workin Paper Series - No.16.02.

BUCHER, E., FIESELER, C. \& LUTZ, C. (2016). "What's Mine is Yours (For a Nominal Fee) - Exploring the Spectrum of Utilitarian to Altruistic Motives for InternetMediated Sharing", Computers in Human Behavior, 62(1):316-326.

CANNON, S. \& SUMMERS, L.H. (2014). "How Uber and the Sharing Economy Can Win Over Regulators", Harvard Business Review, October 13th.

CRAMER, J. \& KRUEGER, A.B. (2016). "Disruptive Change in the Taxi Business: The Case of Uber." American Economic Review, 106 (5): 177-82.

ÇABUK, S., SÜDAŞ, H.D. \& ZEREN, D. (2015). "SahipOlmakYerinePaylaşmak: TüketicilerinPaylaşmaDavranışlarınınUnsurlarınıBelirlemeyeYönelikBirÇalışma”, ÇankırıKaratekinÜniversitesiSosyalBilimlerEnstitüsüDergisi, 6 (1): 151-168. 
DREYER, B., FREUND, F.L., HAMANN, R. \& FACCER, K. (2017). "Upsides and Downsides of the Sharing Economy: Collaborative Consumption Business Models' Stakeholder Value Impacts and Their Relationship to Context", Technological Forecasting \& Social Change, 125 (1): 87-104.

ERTZ, M., DURIF, F. \& ARCAND, M. (2016). “Collaborative Consumption: Conceptual Snapshot at a Buzzword”, Journal of Entrepreneurship Education, 19 (2): 1-23.

ERTZ, M., DURIF, F. \& ARCAND, M. (2016). "Collaborative Consumption or the Rise of the Two-Sided Consumer", The International Journal Of Business \& Management, 4 (6): 195-209.

ERTZ, M., DURIF, F. \& ARCAND, M. (2017).“Dual Roles of Consumers: Towards an Insight into Collaborative Consumption Motives”, International Journal of Market Research, 59 (6).

HELLWIG, K., MORHART, F., GIRARDIN, F. \& HAUSER, M. (2015). "Exploring Different Types of Sharing: A Proposed Segmentation of the Market for Sharing Businesses", Psychology \& Marketing, 32 (9): 891-906.

HSU, C.L. \& LIN, J.C.C. (2008). Acceptance of Blog Usage: The Roles of Technology Acceptance, Social Influence and Knowledge Sharing Motivation, Information \& Management, 45 (1):65-74.

HWANG, J., \& GRIFFITHS, M. A. (2017). "Share More, Drive Less: Millennials Value Perception and Behavioral Intent in Using Collaborative Consumption Services", Journal of Consumer Marketing, 34(2): 132-146.

KIŞI, N. (2018). "Paylaşım Ekonomisinin Ulaşım Sektörüne Yansımaları: Uber Örneği”, Uluslararası Yönetim ve Sosyal Araştırmalar Dergisi, 5 (10): 57-68.

LAMBERTON, C.P. \& ROSE, R.L. (2012). "When is Ours Better Than Mine? A Framework for Understanding and Altering Participation in Commercial Sharing Systems", Journal Marketing, 76(7): 109-125.

LI, M. (2020). Uber Future Value Prediction Using Discounted Cash Flow Model. American Journal of Industrial and Business Management, 10 (1): 30-44.

MAXHAM, J.G. \& NETEMEYER, R.G. (2002). Modeling Customer Perceptions of Complaint Handling Over Time: The Effects of Perceived Justice on Satisfaction and Intent", Journal of Retailing, 78 (4): 239-252.

MIRALLES, I., DENTONI, D. \& PASCUCCI, S. (2017). "Understanding the Organization of Sharing Economy in Agri-Food Systems: Evidence from Alternative Food Networks in Valencia", Agriculture and Human Values, 34 (4): 833-854.

MONT, O. (2004). "Institutionalisation of Sustainable Consumption Patterns Based on Shared Use", Ecological Economics, 50(1-2): 135-153.

MÖHLMANN, M. (2015). “Collaborative Consumption: Determinants of Satisfaction and the Likelihood of Using a Sharing Economy Option Again", Journal of Consumer Behavior, 14(3):193-207. 
OZANNE, L.K. \& BALLANTINE, P.W. (2010). "Sharing as a Form of Anti-Consumption? An Examination of Toy Library Users", Journal of Consumer Behavior, 9 (6): 485 498.

PARK, H. \& ARMSTRONG, M.J. (2017). "Collaborative Apparel Consumption in the Digital Sharing Economy: An Agenda for Academic Inquiry”, Journal of Consumer Studies, 41 (5): 1-10.

PEDERSEN, E.R.G. \& NETTER, S. (2015). “Collaborative Consumption: Business Model Opportunities and Barriers for Fashion Libraries", Journal of Fashion Marketing and Management, 19 (3): 258-273.

PISCICELLI, L., COOPER, T. \& FISHER, T. (2015). “The Role of Values in Collaborative Consumption: Insights From a Product-Service System for Lending and Borrowing in the UK", Journal of Cleaner Production, 97(1):21-29.

PIZZOL, H.D., ALMEIDA, S.O. \& SOARES, C. (2017). Collaborative Consumption: A Proposed Scale for Measuring the Construct Applied to A Carsharing Setting, Sustainability, 9(703):1-16.

RASALAM, J., \& ELSON, R. J. (2019). Cybersecurity And Management's Ethical Responsibilities: The Case Of Equifax And Uber. Global Journal Of Business Pedagogy, 3 (3): 8-15.

RAUCH, D.E. \& SCHLEICHER, D. (2015). “Like Uber, but for Local Government Law: The Future of Local Regulation of the Sharing Economy", Ohio State Law Journal, 76 (4): 901-963.

ROGERS, B. (2017). "The Social Costs of Uber", University of Chicago Law Review Online, 82 (1): 85-102.

ROOS, D. \& HAHN, R. (2017). "Does Shared Consumption Affect Consumers' Values, Attitudes, and Norms? A Panel Study", Journal of Business Research, 77(1): 113-123.

SCHIFFMAN, LG. \&KANUK, L.L. (1991).Consumer, $4^{\text {th }}$ edition, Prentice-Hall International.

TUSSYADIAH, I. (2015). "An Exploratory on Drivers and Deterrents of Collaborative Consumption in Travel", pp.817-839, in Tussyadiah, I \&Inversini, A. (Eds.), Information \& Communication Technologies in Tourism 2015, Switzerland: Springer International Publishing.

TZUR, A. (2019). Uber Über Regulation? Regulatory Change Following The Emergence Of New Technologies in The Taxi Market. Regulation \& Governance, 13 (3): 340-361.

WALLSTEN, S. (2015). "The Competitive Effects of the Sharing Economy: How is Uber Changing Taxis?”, Technology Policy Institute, https://www.ftc.gov/system/files/documents/public_comments/2015/06/0191296334.pdf

VENKATESH, V. \& DAVIS, F.D. (2000). A Theoretical Extension of The Technology Acceptance Model: Four Longitudinal Field Studies, Management Science, 46 (2):186-204. 


\section{[1] Forbes.Com /December}

Https:/Www.Forbes.Com/Sites/Greatspeculations/2018/12/03/How-Uber-Could-Justify-A120- Billion-Valuation/\#6aab05b07f9b (Last Accessed 17 February 2019) "TREFIS TEAM (2018) How Uber Could Justify A \$120 Billion Valuation”

[2] https://www.cnnturk.com/ekonomi/turkiye/taksicilerin-saldirilari-ubere-yaradi-kullanicisayisi-5-kat-artti

\section{Ek1. Faktör Yükleri}

\begin{tabular}{|c|c|c|c|c|c|c|c|c|c|c|c|}
\hline & F1 & F2 & F3 & F4 & F5 & F6 & F7 & F8 & F9 & F10 & F11 \\
\hline VP1 & .887 & & & & & & & & & & \\
\hline VP3 & .887 & & & & & & & & & & \\
\hline VP2 & & .901 & & & & & & & & & \\
\hline VP4 & & .901 & & & & & & & & & \\
\hline KN1 & & & .952 & & & & & & & & \\
\hline KN2 & & & .939 & & & & & & & & \\
\hline KN3 & & & .931 & & & & & & & & \\
\hline TN1 & & & & .943 & & & & & & & \\
\hline TN2 & & & & .940 & & & & & & & \\
\hline TN3 & & & & .906 & & & & & & & \\
\hline GU1 & & & & & .938 & & & & & & \\
\hline GU2 & & & & & .920 & & & & & & \\
\hline GU3 & & & & & .911 & & & & & & \\
\hline GV1 & & & & & .905 & & & & & & \\
\hline GV2 & & & & & .879 & & & & & & \\
\hline SE1 & & & & & & .944 & & & & & \\
\hline SE2 & & & & & & .943 & & & & & \\
\hline EK1 & & & & & & & .951 & & & & \\
\hline EK2 & & & & & & & .930 & & & & \\
\hline EK3 & & & & & & & .894 & & & & \\
\hline AE1 & & & & & & & & .916 & & & \\
\hline AE2 & & & & & & & & .915 & & & \\
\hline SY1 & & & & & & & & & .903 & & \\
\hline SY2 & & & & & & & & & .851 & & \\
\hline SY3 & & & & & & & & & .805 & & \\
\hline EĞ1 & & & & & & & & & & .962 & \\
\hline EĞ2 & & & & & & & & & & .954 & \\
\hline EĞ3 & & & & & & & & & & .939 & \\
\hline IYY1 & & & & & & & & & & & .934 \\
\hline IYY2 & & & & & & & & & & & .933 \\
\hline ACV & 78.7 & 81.3 & 88.4 & 86.4 & 82.9 & 88.9 & 85.7 & 83.9 & 72.9 & 90.5 & 87.1 \\
\hline CAL & .730 & .770 & .934 & .921 & .948 & .874 & .916 & .807 & .809 & .947 & .851 \\
\hline
\end{tabular}


Açıklama: Orijinali tek boyutlu olan "Varolan Paylaşım Ölçeği” yapılan faktör analizinde iki faktör olarak sonuçlanmış; bu faktörlere verici paylaşımlar ve alıcı paylaşımlar isimleri verilmiştir. İkame Yarar ölçeğinin son ifadesi (IYY3) düşük faktör yükü nedeniyle faktör analizinden çıkarılmıştır.

Ek2. Korelasyon Analizi Bulguları

\begin{tabular}{|c|c|c|c|c|c|c|c|c|c|c|c|}
\hline & $\overline{V E}$ & $\mathbf{A L}$ & KN & TN & GÜ & SE & EK & $\mathbf{A E}$ & SY & EĞ & $\overline{\mathbf{I I Y}}$ \\
\hline VE & 1 & & & & & & & & & & \\
\hline $\mathbf{A L}$ & .268 & 1 & & & & & & & & & \\
\hline $\mathbf{K N}$ & .144 & .133 & 1 & & & & & & & & \\
\hline TN & .137 & $\begin{array}{l}.166 \\
* *\end{array}$ & .863 & 1 & & & & & & & \\
\hline Gய̈ & .147 & .146 & .647 & .713 & 1 & & & & & & \\
\hline SE & .021 & .091 & .572 & .606 & .616 & 1 & & & & & \\
\hline EK & .179 & .122 & .473 & .507 & .435 & $\begin{array}{l}369 \\
* *\end{array}$ & 1 & & & & \\
\hline$\overline{A E}$ & .026 & .095 & .480 & $\begin{array}{c}.508 \\
* *\end{array}$ & .441 & .508 & .444 & 1 & & & \\
\hline SY & .105 & .089 & .626 & .662 & .617 & .644 & .484 & $\begin{array}{l}.634 \\
* * *\end{array}$ & 1 & & \\
\hline$\overline{\mathbf{E G}}$ & .153 & .083 & .654 & $\begin{array}{l}.689 \\
* * \\
* *\end{array}$ & .677 & $\begin{array}{l}.575 \\
* *\end{array}$ & .560 & .533 & .791 & 1 & \\
\hline$\dot{\mathbf{I} Y}$ & .112 & .114 & $\begin{array}{l}.687 \\
* *\end{array}$ & $\begin{array}{l}.698 \\
* *\end{array}$ & $\begin{array}{l}.608 \\
* *\end{array}$ & .545 & .573 & $\begin{array}{l}.660 \\
* * *\end{array}$ & $\begin{array}{l}.699 \\
* *\end{array}$ & $\begin{array}{l}.752 \\
* * *\end{array}$ & 1 \\
\hline
\end{tabular}

\section{Ek3. Araştırmada Kullanılan Ölçekler}

\begin{tabular}{|l|l|}
\hline \multicolumn{2}{|c|}{ Bireylerin Var Olan Paylaşım Davranışları (İçsel) } \\
\hline VP1 & Aile bireylerine ya da arkadaşlarıma birşeyleri ödünç vermeyi severim \\
\hline VP2 & Birşeyleri satın almak yerine başkalarından ödünç almaya eğilim gösteririm \\
\hline VP3 & Sahip olduğum şeyleri başkalarıyla sık sık paylaşmaya çalışırım \\
\hline VP4 & Birşeyleri satın almak yerine başkalarıyla paylaşarak kullanmayı tercih ederim \\
\hline
\end{tabular}




\section{Bireylerin UBER Platformunu Kullanma Niyeti}

KN1 UBER sistemini kullanmayı düşünürdüm.

KN2 Muhtemelen UBER'i kullanıyor olurdum.

KN3 Gelecekte UBER'i kullanma niyetim var.

\section{Bireylerin UBER Kullanmayı Tavsiye Etme Niyeti}

TN1 UBER'i arkadaşlarıma öneririm.

TN2 UBER hakkında çevreme olumlu şeyler anlatmam muhtemeldir.

TN3 Eğer arkadaşlarım taksiye binmek isterse ve orada UBER hizmet veriyorsa, onlara UBER'i denemelerini söylerim

\begin{tabular}{|l|l|}
\hline \multicolumn{2}{|c|}{ Bireylerin UBER Platformuna İlişkin Algıladığı Güven (1) } \\
\hline GU1 & UBER'e güveniyorum. \\
\hline GU2 & UBER son derece güvenli hizmet sunmaktadır. \\
\hline GU3 & UBER'in işletme felsefesine güveniyorum. \\
\hline
\end{tabular}

\begin{tabular}{|l|l|}
\hline \multicolumn{2}{|c|}{ Bireylerin UBER Platformuna İlişkin Algıladığı Güven (2) } \\
\hline GV1 & UBER dürüst bir işletmedir. \\
\hline GV2 & UBER müşterilerini önemser. \\
\hline
\end{tabular}

\section{Sosyal Etki}

SE1 Benim için önemli olan insanlar, UBER'i denemem gerektiğini söylüyor. 
SE2 Davranışlarım üzerinde etkisi olan insanlar, beni UBER'i kullanmaya teşvik ediyor.

\begin{tabular}{|l|l|}
\hline \multicolumn{2}{|c|}{ Algılanan Ekonomik Yarar } \\
\hline EK1 & UBER, yeterince para tasarrufu yapmamı sağlardı. \\
\hline EK2 & UBER, seyahat (taksi) masraflarımı düşürmemi sağlardı. \\
\hline EK3 & $\begin{array}{l}\text { UBER, daha az para harcayarak, yüksek kalitede bir ulaşım hizmeti almamı } \\
\text { sağlardı. }\end{array}$ \\
\hline
\end{tabular}

\begin{tabular}{|l|l|}
\hline \multicolumn{2}{|c|}{ Algılanan Anti- Endüstri Yarar } \\
\hline AE1 & UBER, taksicilik sektörüne karşı çıkmamı sağlardı. \\
\hline AE2 & $\begin{array}{l}\text { UBER'i kullanarak, taksicilerin pazarlama oyunlarını elimin tersiyle itebiliyor } \\
\text { olurdum. }\end{array}$ \\
\hline
\end{tabular}

\begin{tabular}{|l|l|}
\hline \multicolumn{2}{|c|}{ Algılanan Sosyal Yarar } \\
\hline SY1 & $\begin{array}{l}\text { UBER, aynı kafada olduğum insanlardan oluşan bir grubun parçası olmamı } \\
\text { sağlardı. }\end{array}$ \\
\hline SY2 & Çevremdeki arkadaşlarım da UBER kullanmama onay verirlerdi. \\
\hline SY3 & Ailem, UBER'i kullanmamı onaylardı. \\
\hline
\end{tabular}

\begin{tabular}{|l|l|}
\hline \multicolumn{2}{|l|}{ Algılanan Eğlence Yararı } \\
\hline EĞ1 & UBER'den hizmet alırken keyif alırdım. \\
\hline EĞ2 & UBER'i kullanmak eğlenceli olurdu. \\
\hline EĞ3 & UBER'i eğlenerek kullanırdım. \\
\hline
\end{tabular}




\begin{tabular}{|c|l|}
\hline \multicolumn{2}{|c|}{ Algılanan İkame Yararı } \\
\hline İY1 & $\begin{array}{l}\text { UBER'den hizmet almak, taksicilerden hizmet almanın tüm işlevlerini yerine } \\
\text { getirirdi. }\end{array}$ \\
\hline İY2 & $\begin{array}{l}\text { UBER kullanarak bir yerlere gidebilmek, taksi kullanarak bir yere gidebilmenin } \\
\text { iyi bir alternatifi olurdu. }\end{array}$ \\
\hline İY3 & $\begin{array}{l}\text { UBER'in hizmetleri taksicilerin sunduğu hizmetlerin yerine geçmezdi. Hiçbir } \\
\text { zaman taksicilerin sunduğu hizmetleri yerine getiremezdi. Çünü Taksiye binmek } \\
\text { ile UBER'i kullanmak birbirinden tamamen apayrı şeylerdir (-) }\end{array}$ \\
\hline
\end{tabular}

